\title{
Context Matters: The Effect of Textual Tone on the Evaluation of Mediated Social Touch
}

\author{
Sima Ipakchian Askari ${ }^{(\bowtie)}$, Antal Haans, Pieter Bos, Maureen Eggink, \\ Emily Mengfei Lu, Fenella Kwong, and Wijnand IJsselsteijn \\ Eindhoven University of Technology, Eindhoven, The Netherlands \\ s.ipakchian.askar@tue.nl
}

\begin{abstract}
Mediated Social Touch (MST) promises interpersonal touch over a distance through haptic or tactile displays. Tests of the efficacy of MST often involve attempts to demonstrate that effects of social touch (e.g., on affective responses or helping behavior) can be replicated with MST. Results, however, have been mixed. One possible explanation is that contextual factors have not sufficiently been taken into account in these experiments. A touch act is accompanied by other verbal and non-verbal expressions, and whom we touch, when, and in what manner is regulated through social and personal norms. Previous research demonstrated, amongst others, effects of gender and the facial expression of the toucher on the recipients' touch experience. People can use expressions of the toucher's emotions as a cue to anticipate the meaning of the ensuing social touch. This current study examines whether emotions expressed in text (i.e., textual tone) affects the meaning and experience of MST. As expected we found textual tone to affect both the comfortableness of the touch as well as its perceived meaning. Limitations and implications are discussed.
\end{abstract}

Keywords: Mediated social touch - Textual tone - Affective haptic devices · Computer mediated communication $\cdot$ Haptic feedback

\section{Introduction}

Social touch plays an important role in human development, interpersonal communication, and well-being [1]. However, circumstances exist when it is not possible to have skin-to-skin contact, e.g. due to geographical separation. Mediated Social Touch (MST) devices address this problem by facilitating touch over distance through the use of tactile or haptic displays [2]. Research and design efforts that demonstrate what is possible technology-wise are numerous, and span a wide range of applications: from giving your child a hug, perform arm-wrestling, to giving a squeeze to another person [2]. Despite this work, research on the extent to which the effects of natural social touch can be replicated with MST has shown mixed results. Whereas Haans et al. [3] showed that the Midas touch-increased helping behaviour and willingness to comply to request [4] - may be replicated with vibrotactile MSTs, no effects of MST on, e.g., reducing stress have been established [5,6], unlike prior work in the field of naturalistic social touch [1,7]. One possible explanation is that current day tactile and haptic displays cannot mimic a real social touch with sufficient fidelity. At the same time, 
social touch is more than tactile stimulation. Indeed, a touch act is always combined with other verbal and non-verbal cues alone (e.g., physical closeness [3]) which together shape its meaning and convey the perceived intention of the toucher.

Moreover, research aimed at demonstrating response similarities between real and MST has not always taken into account that where, when and whom we touch, is regulated by social norms. As a result, the potential stress-reducing effects of MST have been tested in contextual settings that appear to be rather unnatural; e.g. having male strangers hold hands through MST after having watched an emotionally charged movie [5, 6]. Existing research suggests that such contextual factors as the gender of the toucher can influence touch experience. For example, Gazzola et al. [9] showed that the primary somatosensory cortex differs in response depended on whether participants believed they were stroked by a male as compared to a female actor. Similarly Harjunen et al. [8] found the facial expression of a virtual agent to affect touch perception, with participants reporting more pleasant evaluations when being touched by a happy agent in comparison to an angry one. The perceived intensity of the touch also was found to depend on the agent's expression. According to Harjunen et al. [8], people use facial expressions of emotions as a cue to anticipate the meaning of an upcoming social touch. Such emotions and the resulting anticipation do not solely rely on facial expression but can also be derived from written text [10].

Therefore, in the present paper, we test whether the tone of a textual message affects the experience of an ensuing MST in terms of social comfortability with the touch, the perceived meaning of the touch, and the physical sensation of the touch.

\section{Method}

\subsection{Participants}

Ninety-three participants were recruited through the participant database of TU/e. Eight participants were excluded due to technical errors or for neglecting to fill in the questionnaire after each received touch. Of the remaining 85 participants, 46 were male and 39 female, with a mean age of $\mathrm{M}_{\text {age }}=27$ years $(\mathrm{SD}=10$; range: 19 to 64). Participants' self-reported ethnicity include 60\% Dutch, 18.8\% Indian, and 21.2\% others. Participants received 5 euros as compensation (7 euros for externals).

\subsection{Design}

We conducted a two-condition (receiving a MST in a friendly vs. dominant textual tone context) within-subject design. Dependent variables were perceived comfortableness, smoothness, and hardness of the touch, as well as its perceived meaning and match with the tone of the message. Participants received two MSTs from a female confederate during an online question and answer (Q\&A) conversation. The conversation was fully scripted around the topic of childhood (i.e., all questions and corresponding answers were fixed; see Table 1). The participant asked the questions, which the confederate answered. The confederate was one out of three randomly assigned females, due to limited availability of confederates. The textual tone of one answer was 
designed to be friendly and the tone of another to be dominant (see Table 1). The remaining four answers were written in a neutral tone. The same MST was given to the participant after the friendly and the dominant answers. The order of these two touches - and thus the order of the questions with the dominant and friendly answers-were counterbalanced across participants. For this purpose, two Q\&A scripts were designed. In one set the 2nd answer was friendly, and the 4th dominant, in the other vice versa.

Table 1. Q\&A script.

\begin{tabular}{l|l}
\hline Question & Answer \\
\hline $\begin{array}{l}\text { Q1: Do you think your childhood had a } \\
\text { major impact on who you are today? }\end{array}$ & $\begin{array}{l}\text { Yes my childhood did influence me. How I } \\
\text { was raised, which people I considered my } \\
\text { friends, things that have happened, it all } \\
\text { shaped me }\end{array}$ \\
\hline $\begin{array}{l}\text { Q2: What was your favorite toy as a child? } \\
\text { and why? }\end{array}$ & $\begin{array}{l}\text { Lego. I played with that a lot. I really } \\
\text { enjoyed building complete cities with my } \\
\text { brothers. Each year we all would get a new } \\
\text { set for birthday. it was something we really } \\
\text { looked forward to doing together as a family }\end{array}$ \\
\hline $\begin{array}{l}\text { Q3: Are you still in touch with the people } \\
\text { you were close with during your childhood? }\end{array}$ & $\begin{array}{l}\text { Yeah, I tried to keep in touch with a bunch of } \\
\text { them. I still hang out or chat with a few of } \\
\text { them, but most of them do not live close by } \\
\text { so it is hard to see each other regularly }\end{array}$ \\
\hline $\begin{array}{l}\text { Q4: What was your favorite subject at } \\
\text { elementary school? and why? }\end{array}$ & $\begin{array}{l}\text { Maths, not just because it was easy, but the } \\
\text { teacher was useless! He couldn't even } \\
\text { answer the more complex questions in the } \\
\text { back of the book. He told me to wait and ask } \\
\text { the teacher in the following year. That is } \\
\text { when I learnt that I am better than the rest }\end{array}$ \\
\hline $\begin{array}{l}\text { Q5: What was your dream job when you } \\
\text { childhood? } \\
\text { since young? Has that dream job changed }\end{array}$ & $\begin{array}{l}\text { I wanted to be a physician. Yes it has } \\
\text { changed. You learn more about the world, } \\
\text { and get to know what you really like and are } \\
\text { good at. Now I want to develop tech that } \\
\text { helps people with aging }\end{array}$ \\
\hline $\begin{array}{l}\text { Yeah. Compared to other yes. Parents are } \\
\text { still together, and I did not have to move to } \\
\text { many different cities to change school. I'm } \\
\text { grateful for that }\end{array}$ \\
\hline Nong
\end{tabular}

Note: The answer to Q2 was the friendly and that to Q4 the dominant answer. The order of these two questions within the Q\&A set was counterbalanced across participants.

\subsection{Apparatus and Stimuli}

The experimental setting consisted of two desks facings each other, separated by a full size table divider. On each desk a laptop running Skype Online, a keyboard, and mouse were placed. The confederate's laptop also contained software for sending the MSTs. The tactile stimulus consisted of a caress applied by a finger-tip-sized soft polyurethane 
foam to the non-glabrous skin of the participant's left forearm, at a speed of $3.1 \mathrm{~cm} / \mathrm{s}$ for a duration of $3.9 \mathrm{~s}$ [11], and in the distal direction. The mechanism of the MST device consisted of two sprockets, a tooth belt, and a Nema 17 stepper motor (12 V), and was concealed from view by means of a cardboard box. An Arduino Uno microcontroller was used alongside a TMC2208 driverboard to control the caress. To avoid anticipation of the MST, a sound recording of the MST device was played during the experiment. In addition, participants wore earmuffs.

\subsection{Procedure}

Before entering the room, the participant was notified that the other participant (the confederate) was already waiting in the lab. Upon entering, the participant was introduced to the confederate, who was sitting at the participant's seat, as though she had just tested the MST device. By doing so, we aimed to make it more plausible to the participant that the confederate too was a participant.

Next, the participant was given a cover story explaining that the aim of the experiment was to investigate when MST would be used during a Skype conversation - on the topic of childhood - and how such MSTs are perceived. After assigning, seemingly randomly, the role of interviewer to the confederate and that of interviewee to the participant, the participant was instructed to ask a pre-defined set of questions, and pay attention to the confederate's answers. The full list of questions was placed on the participant's table. The confederate was asked to answer the questions and deliver touches to the participant whenever she found appropriate. In reality, the timing of the MSTs was scripted. Both were instructed to complete a short survey each time a MST was used. After signing the informed consent, the MST device was placed over the participant's forearm, and the confederate was explained how to initiate a MST. The participant then received two MSTs to familiarize with the sensation. Next, both were asked to put on their earmuffs, after which the Q\&A began. After each of the two MSTs, the participant completed the touch experience questionnaire. After the last question, the participant notified the experimenter. The background sound was paused, and a general questionnaire was handed out for both to fill in. Finally, the participant was payed, and informed that the debriefing would be sent by email later.

\subsection{Measures}

The touch experience questionnaire consisted of several open- and closed-ended questions. The 12 closed-ended items were 7-pt semantic differentials: 6 on the comfortableness (e.g. uncomfortable vs. comfortable; unacceptable vs. acceptable), 3 on the smoothness (relaxed vs. tense; smooth vs. rough; elastic vs. rigid), and 3 on the hardness of the touch (light vs. heavy; soft vs. hard; short vs. long). Open-ended questions concerned the perceived meaning of the touch, and whether its physical characteristics matched that perceived meaning. The latter was asked alongside a 5-pt response scale (not matched - matched).

Two separate factor analyses were performed on the polychoric correlation matrix of the comfortableness, hardness and smoothness items: one on the responses after the first, the other on the responses after the second MST. We used principal (axis) 
factoring as extraction, and oblique oblimin as rotation method. Prior to the analysis, items were inspected for missing values, low inter-item correlations, and low KMO values. Based on parallel analysis [12], three factors were extracted in both sets of responses. Except for one item (short vs. long; $\lambda \leq .50$ ), all items loaded on the expected factor with $\lambda \geq .67$. Therefore the former item was excluded from the analysis. We used the summated scale method to calculate factor scores. Cronbach's alpha values were $\alpha \geq .87$ for comfortableness, $\alpha \geq .83$ for hardness and $\alpha \geq .80$ for smoothness. For one person, no smoothness score could be calculated due to missing values. All three variables were found to be normally distributed.

The general questionnaire consisted of demographical questions (i.e. age, ethnicity and gender), 2 items measuring likability of the confederate on a 7-pt scale (e.g. unfavourable - favourable), 6 items measuring touch avoidance on a 5-pt scale [13], and 2 open-ended question concerning participants' thoughts on the interview setting and the MST device. Factor analysis - using the same method as described abovedemonstrated that the six touch avoidance items all loaded on a single factor. Factor scores were calculated with the summated scale method, and the reliability was $\alpha=.82$. For one person, no touch avoidance score could be calculated due to missing values. Since touch aversion was not normally distributed, we used a $1 /$ sqrt transformation. Likability of the confederate was also calculated using the summated scale method, and the reliability was $\alpha=.87$. For one person, no likability score could be calculated due to missing values. Likability was not normally distributed and no satisfactory transformation could be found.

\section{Results}

\subsection{Comfortableness, Smoothness, and Hardness}

To test the effect of textual tone on perceived comfortableness, smoothness, and hardness of the touch, we used paired sample $t$ tests. Since three tests were conducted, we set the confidence level at $\alpha=.016$. We found textual tone to affect comfortableness to a statistically significant extent, with $t(84)=3.4, p=.001$. The MST was perceived to be more comfortable when combined with a friendly tone (see Table 2). No statistically significant effect was found on smoothness and hardness, with $t$ $(83)=1.8, p=.075$ and $t(84)=-2.0, p=.046$ respectively. Exclusion of outliers (with $|\mathrm{Z}|>3$ ) did not affect the interpretation of the results.

Table 2. Mean comfortableness, smoothness and hardness and their standard deviations (SD) for the friendly and dominant textual tone condition

\begin{tabular}{l|l|l}
\hline & \multicolumn{2}{|l}{ Mean (SD) } \\
\cline { 2 - 3 } & Friendly & Dominant \\
\hline Comfortableness & $4.57(1.16)$ & $4.23(.98)$ \\
\hline Smoothness & $4.02(1.15)$ & $3.79(1.11)$ \\
\hline Hardness & $3.45(1.21)$ & $3.74(1.21)$ \\
\hline
\end{tabular}


We found self-reported likability of the confederate to be positively correlated with comfortableness (rho $\geq .31 ; p \leq .010$ ), but not with smoothness and hardness (| $r h o \mid \leq .13 ; p \geq .241)$. No correlations were found between these dependent variables and touch avoidance $(|r| \leq .13 ; p \geq .26)$. To explore how likability of the confederate may affect the observed effect of textual tone on perceived comfortableness, we conducted a repeated-measures ANOVA with mean centred likability as covariate. The main effect of textual tone remained statistically significant with $\mathrm{F}$ $(1,82)=11.3$, and $p=.001$. While likability was significantly related to comfortableness, with $\mathrm{F}(1,82)=13.8$, and $p<.001$, there was no significant textual tone by likability interaction, with $\mathrm{F}(1,82)=0.8$, and $p=.382$.

\subsection{Perceived Meaning of the Touch}

We used content analysis to investigate differences in perceived meaning of the touch between the two conditions. Responses were coded into one of the following categories: positive (phrases including, e.g., happiness, excitement, nostalgia, and fun), negative (phrases including, e.g., frustration, anger, better, arrogance), and other (i.e., not fitting the other two categories). Responses were coded independently by the first and second author. Cohen's kappa showed a moderate level of agreement: 0.74 [14]. Any disagreement between the authors was resolved (see Table 3 for observed category counts). A Chi-square test showed a statistically significant difference in category counts between the friendly and dominant tone condition, with $\chi^{2}(2)=25.5$, $p<0.001$. To confirm that this difference was indeed due to a relative change in positively and negatively charged phrases, we repeated the Chi-square test, but this time with the other category removed from the analysis. This confirmed that participants used comparatively more positive than negative words in the friendly condition than in the dominant condition, and vice versa, with $\chi^{2}(1)=18.8, p<0.001$.

Table 3. Distribution of negative, other, and positive coded meaning of MST for the friendly and dominant textual tone condition

\begin{tabular}{l|c|l|l}
\hline & Negative & Other & Positive \\
\hline Friendly textual tone & 1 & 34 & 50 \\
\hline Dominant textual tone & 12 & 51 & 20 \\
\hline
\end{tabular}

From the proportion of responses coded as "other" (see Table 1), it becomes clear that there was more confusion regarding the meaning of the touch in the dominant condition than in the friendly condition. Although some participants assigned a negative meaning to the touch (e.g., "A bit of anger and frustration about the lack of competence of the math teacher" or "To support the statement that the participant is better than the rest"), others used more positive terms (e.g., "That she felt sort of proud of being the best in maths when she was in elementary school. Despite the teacher being useless"). Many, however, were ambivalent about the meaning (e.g., "I did not really understand. I am not sure this would make sense in a similar context in real life." 
and "I actually really don't know. The touch did not make sense in this case."). Responses in the friendly condition were less ambivalent, and many described the touch as positive (e.g., "A feeling of joyfulness when thought of the Lego." or "To show her warm memory with her family, the warm feeling about the family activities". Although less than in the dominant condition, the meaning of the friendly touch also remained unclear to many (e.g., "I am again not sure." and "I don't know").

With more ambivalence as to the meaning of the touch in the dominant textual tone condition, one would have expected that the physical characteristics of the MST would match less well with the dominant answer as compared to the friendly answer. However, responses to the 5-pt item tapping into the extent of such a match were rather similar between the two conditions, with $\mathrm{M}=3.02(\mathrm{SD}=1.14)$ and $\mathrm{M}=2.92$ (SD 1.19), respectively. Similarly, the responses to the open-format question on the match between meaning and physical characteristics yield similar explanations for why the touch matched or mismatched for both the dominant as well as the friendly conditions. The reasons participants mentioned were often attributed to tactile stimulations of the touch or emotional content of the message. Additionally, participants expressed doubt or confusion regarding the meaning of the MST.

\section{Discussion}

Qualitative and quantitative results showed that textual tone can influence touch experience. Consistent with existing research [8,9], we found a significant difference in the perceived comfortableness of touch between the friendly and dominant textual tone. In contrast to previous studies [8], however, the effects of textual tone on perceived smoothness and hardness of the tactile stimulation, although in the expected direction, were not found to be statistically significant.

The content analysis revealed that, as expected, textual tone affected the perceived meaning of the MST: Participants used comparatively more positive than negative words in the friendly condition than in the dominant condition, and vice versa. However, we participants to be rather ambivalent as to the meaning of the touch in the dominant textual tone condition, where most of the responses were coded as "positive" or "other". One possible explanation is that the tactile stimulus did not match well with the dominant textual tone answer. A caress is typically used in affective settings and found to communicate emotions such as love and sympathy [15], and may thus match better with the friendly than the dominant textual tone. Apparently, both the physical characteristics of the touch as well as its context are taken into account in the processing of a touch's meaning.

There were several limitations to the present work. First, due to time constraints of the project multiple confederates were used. Second, several participants were skeptical of the cover story, believing the interview was scripted and/or the fellow participant being a confederate.

Despite these limitations, our findings demonstrate that the textual tone of a chat message can change how people experience MST and what meaning they assign to it. As such, our findings are in line with previous studies, demonstrating that contextual factors affect how a tactile stimulus provided by a MST device is experienced, and thus 
its effect on the receiver's behavior as well. Consequently research aimed at testing the efficacy of MST (e.g., by demonstrating response similarities with naturalistic touch) should design carefully not only the tactile stimulus but also the context in which the touch act is delivered. Nonrepresentative and unanticipated context, such as when having two male strangers holding hands after having watched an emotionally charged movie, may not elucidate the possible beneficial effects of MST.

Acknowledgments. We thank Martin Boschman, Nasir Abed, Aart van der Spank and Twan Aarts for their continued assistance during development of the MST device.

\section{References}

1. Cascio, C.J., Moore, D., McGlone, F.: Social touch and human development. Dev. Cogn. Neurosci. 35, 5-11 (2019)

2. Huisman, G.: Social touch technology: a survey of haptic technology for social touch. IEEE Trans. Haptics 10(3), 391-408 (2017)

3. Haans, A., de Bruijn, R., IJsselsteijn, W.A.: A virtual midas touch? Touch, compliance, and confederate bias in mediated communication. J. Nonverbal Behav. 38(3), 301-311 (2014). https://doi.org/10.1007/s10919-014-0184-2

4. Crusco, A.H., Wetzel, C.G.: The Midas touch: the effects of interpersonal touch on restaurant tipping. Pers. Soc. Psychol. Bull. 10(4), 512-517 (1984)

5. Erk, S.M., Toet, A., Van Erp, J.B.: Effects of mediated social touch on affective experiences and trust. PeerJ 3, e1297 (2015)

6. Cabibihan, J.-J., Zheng, L., Cher, C.K.T.: Affective tele-touch. In: Ge, S.S., Khatib, O., Cabibihan, J.-J., Simmons, R., Williams, M.-A. (eds.) ICSR 2012. LNCS (LNAI), vol. 7621, pp. 348-356. Springer, Heidelberg (2012). https://doi.org/10.1007/978-3-642-34103-8_35

7. Ditzen, B., et al.: Effects of different kinds of couple interaction on cortisol and heart rate responses to stress in women. Psychoneuroendocrinology 32(5), 565-574 (2007)

8. Harjunen, V.J., Spapé, M., Ahmed, I., Jacucci, G., Ravaja, N.: Individual differences in affective touch: behavioral inhibition and gender define how an interpersonal touch is perceived. Pers. Individ. Differ. 107, 88-95 (2017)

9. Gazzola, V., Spezio, M.L., Etzel, J.A., Castelli, F., Adolphs, R., Keysers, C.: Primary somatosensory cortex discriminates affective significance in social touch. Proc. Natl. Acad. Sci. 109(25), E1657-E1666 (2012)

10. Gill, A.J., Gergle, D., French, R.M., Oberlander, J.: Emotion rating from short blog texts. In: Proceedings of the SIGCHI Conference on Human Factors in Computing Systems, pp. 1121-1124 (2008)

11. Löken, L.S., Wessberg, J., McGlone, F., Olausson, H.: Coding of pleasant touch by unmyelinated afferents in humans. Nat. Neurosci. 12(5), 547 (2009)

12. Dinno, A.: Implementing Horn's parallel analysis for principal component analysis and factor analysis. Stata J. 9(2), 291-298 (2009)

13. Wilhelm, F.H., Kochar, A.S., Roth, W.T., Gross, J.J.: Social anxiety and response to touch: incongruence between self-evaluative and physiological reactions. Biol. Psychol. 58(3), $181-202(2001)$ 
14. McHugh, M.L.: Interrater reliability: the kappa statistic. Biochem. Med. 22(3), 276-282 (2012)

15. Huisman, G., Darriba Frederiks, A.: Towards tactile expressions of emotion through mediated touch. In: CHI 2013 Extended Abstracts on Human Factors in Computing Systems, pp. 1575-1580. ACM, New York City (2013)

Open Access This chapter is licensed under the terms of the Creative Commons Attribution 4.0 International License (http://creativecommons.org/licenses/by/4.0/), which permits use, sharing, adaptation, distribution and reproduction in any medium or format, as long as you give appropriate credit to the original author(s) and the source, provide a link to the Creative Commons license and indicate if changes were made.

The images or other third party material in this chapter are included in the chapter's Creative Commons license, unless indicated otherwise in a credit line to the material. If material is not included in the chapter's Creative Commons license and your intended use is not permitted by statutory regulation or exceeds the permitted use, you will need to obtain permission directly from the copyright holder.



